\section{Una serie de casos de pacientes con heridas crónicas después de recibir tratamiento tópico con plata}

\section{Series of cases of patients with chronic wounds after receiving topical treatment with silver}

\author{
Andressa de Oliveira Lopes ${ }^{1, *}$ \\ Silvia Maria Albertini² \\ Regina Helena Squizatto ${ }^{3}$ \\ Rita de Cássia Helú Mendonça Ribeiro ${ }^{4}$ \\ Antonio Alberto Lopes Elias ${ }^{5}$ \\ Nádia Antonia Aparecida Poletti ${ }^{6}$
}

1. Enfermera en Dermatología en el área de heridas. Maestría en Enfermería por la Facultad de Medicina de São José do Rio Preto. São Paulo. Brasil.

2. Maestría en Ciencias de la Salud. Nutricionista y Profesora Asistente del Departamento de Enfermería General. Facultad de Medicina de São José do Rio Preto. São Paulo. Brasil.

3. Maestría en Enfermería. Facultad de Medicina de São José do Rio Preto. São Paulo. Brasil.

4. Profesora Doctora. Departamento de Enfermería General. Facultad de Medicina de São José do Rio Preto. São Paulo. Brasil.

5. Especialista en Ortodoncia y Ortopedia facial. Maestría cursada en la Facultad de Medicina de São José do Rio Preto. São Paulo. Brasil.

6. Profesora Doctora del Departamento de Enfermería General. Facultad de Medicina de São José do Rio Preto. São Paulo. Brasil.

*Autor para correspondencia.

Correo electrónico: andressaolopes79@gmail.com (Andressa de Oliveira Lopes)

\section{RESUMEN}

Muchos son los desafíos hallados en el cuidado de las heridas cutâneas, que alcanzan una proporción aún mayor cuando estas heridas presentan señales clínicas surgidas de infecciones. En gran parte de las instituciones nacionales de asistencia a la salud no es posible identificar y cuantificar los microrganismos presentes en las heridas. Objetivo: Identificar los microorganismos de las heridas crónicas antes y después del tratamiento con una cobertura antimicrobiana con plata y verificar los niveles de proteína $\mathrm{C}$ reactiva y su asociación con las dimensiones de la herida. Casuística y método: Serie de casos con análisis clínicos y de laboratorio de 10 pacientes con heridas crónicas, durante un período de 2 semanas en un ambulatorio de heridas del Hospital de Base/FUNFARME, de la Facultad de Medicina de São José do Rio Preto. Resultados: De los pacientes estudiados, la mayoría (60\%) eran del sexo femenino y un $40 \%$ presentó úlcera vasculogénica. El microorganismo predominante fue Staphylococcus aureus. Hubo inhibición de algunos microrganismos y crecimiento de otros géneros y especies. Se consideró débil la correlación entre el área inicial de la herida y la proteína $\mathrm{C}$ reactiva

(PCR) sérica inicial $(0,05183)$, y entre área final de la herida y la

PCR sérica final $(0,3587)$. Sin embargo, con el aumento del área de la herida hubo un incremento de los niveles séricos de PCR y, con la disminución del área, um reducción de los niveles de PCR. Conclusión: La correlación entre los niveles séricos de PCR y las dimensiones de la herida fueron débiles y no significativas, pero positivas.

PALABRAS CLAVE: Infección de herida, microbiota, plata, proteína $\mathrm{C}$ reactiva.

\section{ABSTRACT}

Many challenges can be found on the care of cutaneous wounds, especially when these wounds present subtle clinical signs of infection. It is not possible to identify and quantify microorganisms in wounds in most national health care institutions. Objectives: To identify the microorganisms of chronic wounds before and after treatment with antimicrobial coverage with silver, and to check the levels of C-reactive protein and its association with the dimensions of the wound. Casuistic and Method: Case series with clinical and laboratory analysis of 10 patients with chronic wounds, during a period of two weeks in a Wound Care Outpatient Clinic / FUNFARME, Medical School of São José do Rio Preto / SP-FAMERP. Results: Of the patients studied, the majority (60\%) were female, and $40 \%$ had vasculogenic ulcer. The predominant microorganism was Staphylococcus aureus. There was inhibition of some microorganisms and growth of other genera and species. We found a weak correlation between initial wound area and initial serum CRP $(0,05183)$, and between final wound area and final serum CRP $(0,3587)$. However, with the increase of the area of the wound, there was an increase in the serum levels of the CRP and, with the decrease of the area, a reduction of the CRP levels. Conclusion: The correlation of serum CRP levels and wound dimensions were weak and not significant; but positive.

KEYWORDS: Wound infection, Microbiota, Silver, C-Reactive Protein. 


\section{У INTRODUCCIÓN}

El proceso de cicatrización se caracteriza por fases estructuradas e interconectadas: coagulación, inflamación, proliferación celular, epitelización y remodelación del tejido cicatricial. La cicatrización debe ser observada durante un período de 4 semanas, y este proceso puede ser interrumpido en cualquiera de las fases por factores extrínsecos e intrínsecos, cuyas causas estén relacionadas con la etiología de la herida, la edad del paciente y la presencia de comorbilidad. Estas heridas pueden ser crónicas o agudas y cuanto más complejas, más crítica será la cicatrización, lo que representa un desafío para el equipo de salud ${ }^{1,2}$.

Todas las heridas son colonizadas; sin embargo, es posible que no presenten características o señales de infección local. La reducción de los microorganismos locales puede facilitar el proceso de cicatrización y en este caso los agentes antimicrobianos se configuran como una alternativa para el tratamiento tópico ${ }^{3}$.

La plata se utiliza como terapia tópica de heridas infectadas desde hace muchos ańos, y distintas investigaciones mencionan que este componente posee un mecanismo de acción contra múltiples objetivos en la célula bacteriana, actuando como bactericida y bacteriostática ${ }^{4,5}$.

Desde el punto de vista comercial, la plata se encuentra de diversas formas; entre ellas, la elemental (p. ej., metálica o nanopartículas), como compuesto inorgánico (p. ej., óxido de plata, sulfato de plata y la sulfadiazina de plata) y como complejo orgánico (p. ej., el alginato de plata y la carboximetilcelulosa de plata). Actualmente, los niveles disponibles de plata en coberturas son de 1 a 100 partículas por millón (ppm) y, según los autores, no presentan un efecto tóxico sistémico ${ }^{5,6}$.

En un estudio realizado con modelos animales se evaluaron los efectos de la plata en tres clínicos microbianos aislados: Escherichia coli, Staphylococcus aureus y Candida albicans. Se utilizaron nanopartículas de plata $(\mathrm{AgNP})$ que se impregnaron en un tejido de algodón y los resultados apuntaron a que $250 \mathrm{ppm}$ de AgNP fueron más eficaces contra las diferentes especies de microrganismos que aquellas que presentaron concentraciones de 60 y $125 \mathrm{ppm}^{7}$.

En la actualidad existen varias investigaciones que tratan sobre la utilización de la plata en las heridas, y los resultados apuntan a que esta debe ser usada de manera selectiva, durante un período limitado de tiempo, que tiene efectos antimicrobianos, mejora la calidad de vida y tiene una buena relación costo-beneficio ${ }^{2-5}$.

La cuestión que rodea esta investigación es si la plata altera la microbiota de la herida y proporciona un microambiente favorable para la cicatrización. De esta forma, el objetivo de este estudio consiste en investigar los microorganismos existentes en las heridas complejas antes y después del tratamiento con una cobertura antimicrobiana compuesta por plata elemental y si existe una relación de los niveles de proteína $\mathrm{C}$ reactiva (PCR) con las dimensiones de la herida.

\section{У CASUÍSTICA Y MÉTODO}

Se trata de un estudio observacional, de tipo serie de casos, de 10 pacientes con heridas complejas. El campo de investigación fue el ambulatorio de heridas del Hospital de Base/FUNFARME, de la Facultad de Medicina de São José do Rio Preto/SP-FAMERP, que se encuadra como referencia en atención de alta complejidad.

Los criterios de inclusión cumplieron las siguientes características: edad superior a los 18 ańos, herida de entre 10 y $15 \mathrm{~cm}$ y bordes delimitados. Se consideraron heridas con: contaminación, colonización, infección local y diseminada. Fueron excluidos los niños, las lesiones por presión sacral, los pacientes que presentasen hipersensibilidad conocida al hidroalginato o a la plata, los implantes quirúrgicos y las mujeres embarazadas o en el período de lactancia.

En el caso de los pacientes, se aplicó un instrumento con el fin de recoger datos demográficos, como: sexo, edad, escolaridad, comorbilidad, peso $(\mathrm{kg})$, altura $(\mathrm{m})$ e índice de masa corporal (IMC). En adultos fue definido como bajo peso un IMC $<18,5 \mathrm{~kg} / \mathrm{m}^{2}$; sobrepeso, un IMC entre 25 y $29,9 \mathrm{~kg} / \mathrm{m}^{2}$, y obesidad, un IMC $>30 \mathrm{~kg} / \mathrm{m}^{2,8}$. Para ancianos, se consideró bajo peso IMC $<22 \mathrm{~kg} / \mathrm{m}^{2}$ y exceso de peso IMC $>27 \mathrm{~kg} / \mathrm{m}^{2,9}$.

Para análisis de laboratorio fueron determinados, al inicio y al final del estudio, valores séricos de PCR; los análisis fueron realizados por el Laboratorio Central del Hospital de Base de São José do Rio Preto-FUNFARME. Para las inflamaciones leves se consideraron infecciones virales, elevaciones en el rango de $1-4 \mathrm{mg} / \mathrm{dl}$, y como inflamaciones más graves e infección bacteriana, concentraciones séricas entre 4 y $20 \mathrm{mg} / \mathrm{dl}^{10}$.

Después de la selección de los pacientes, se aplicó un instrumento con la finalidad de recoger los datos demográficos. Los demás datos caracterizaban la herida y las medidas, tipo, señales de infección, tejidos presentes, características del exudado, coloración y el tiempo de la herida. Los datos recogidos se basaron en el instrumento MEASURE elaborado por Dealey en $1990^{11}$. Durante 15 días se aplicó una cobertura de hidroalginato con saturación máxima de la plata elemental de 20 ppm.

La recolección de la muestra por lavado de la herida fue realizada en el $1 .^{\text {er }}$ y en $18 .^{\circ}$ día, con suspensión del tratamiento con la cobertura durante 3 días, descartando una posible partícula de plata presente en la herida que pudiese interferir en los resultados.

Para la recolección de la muestra, la aspiración por lavado fue realizada tras la limpieza del área perilesional, donde los márgenes de la herida fueron descontaminados con solución de clorhexidina acuosa al 0,2\% y solución fisiológica al 0,9\% (proporción 1/1). La limpieza de la herida fue realizada con solución fisiológica al $0,9 \%$ y el material recolectado fue retirado de la parte más profunda de la herida, aspirado con jeringa de $1 \mathrm{ml}$ y aguja de $13 \times 4,5 \mathrm{~cm}$ con inclinación de $45^{\circ}$, aproximándose al nivel del borde de la herida. Tras la recolección, las muestras fueron depositadas en frasco universal estéril y transportadas inmediatamente al laboratorio en temperatura $\pm 25^{\circ} \mathrm{C}^{12}$.

Conforme al protocolo del hospital, se añadió a las muestras $10 \mathrm{ml}$ de solución salina estéril, agitado en vórtex e incubado durante 24 horas a $35^{\circ} \mathrm{C}$. A continuación fue transferida solamente la solución a un tubo cónico estéril, donde fueron centrifugadas durante 10 minutos a $2.500 \mathrm{rpm}$. A continuación se eliminó el sobrenadante para sembrar el sedimento e insertar el ala microbiológica estéril en el fondo del tubo cónico. El material fue descargado en el borde de una placa de agua y una placa de agar McConkey y sembrado. Se realizó la incubación durante más 24 horas, y en la vigencia de crecimiento fue posible la identificación bacteriana.

El estudio fue aprobado por el Comité de Ética en investigación, involucrando individuos de la Facultad de Medicina de São José do Rio Preto, en cumplimiento de la Resolución 466/12 del Consejo Nacional de Salud - CAAE 46417815.4.0000.5415. Los procedimientos se realizaron una vez que los participantes firmaron el consentimiento libre e informado.

Después de la recolección de los datos, estos fueron planificados en un formulario Excel. El análisis estadístico descriptivo se realizó a partir de los cálculos de las medidas de tendencia central y dispersión y recuentos de frecuencias. Para el análisis estadístico inferencial de las variables cuantitativas se utilizó el test de Kolmogórov-Smirnov para verificar la normalidad de los datos, y la prueba de Wilcoxon de datos paramétricos pareados. Los análisis de correlación se realizaron mediante el método de Spearman. En todos los análisis se consideró estadísticamente significativo un valor de $p \leq 0,05$. El programa utilizado fue el SPSS (IBM, versión 23, 2014). 


\section{RESULTADOS}

El promedio de edad fue de $57,3 \pm 18,3$ ańos (mediana de 58 años), hubo mayor frecuencia del sexo femenino (60\%), y el nivel de escolaridad varió de no alfabetizado a enseńanza media incompleta. La mitad de la muestra no presentaba ninguna comorbilidad y entre quienes presentaban hipertensión arterial esta fue la de mayor ocurrencia (30\%). El promedio de peso corporal fue de $90,6 \pm 25,0 \mathrm{~kg}$ y el promedio de IMC de $30,5 \pm 6,7 \mathrm{~kg} / \mathrm{m}^{2}$, variando de 21,6 a $44,1 \mathrm{~kg} / \mathrm{m}^{2}$; de los 10 pacientes estudiados, 7 (70\%) presentaban exceso de peso, 2 (20\%) eran eutróficos y $1(10 \%)$ tenía bajo peso. Otro hallazgo fue que, de los 3 pacientes hipertensos, 1 era eutrófico, 1 presentaba obesidad de grado I y 1 obesidad de grado III. La tabla 1 presenta las características sociodemográficas y clínicas de los pacientes del estudio.

En cuanto a los tipos de heridas, se comprobó que 4 (40\%) pacientes presentaron úlcera de tipo vasculogénico, $3(30 \%)$ por trauma, $2(20 \%)$ por dehiscencia y $1(10 \%)$ por micosis fungoide. La mediana de duración de las heridas fue de 19 meses; el tiempo mínimo fue de un mes y el máximo, de 120 meses. En relación con la recolección inicial, la mayor área de la herida fue de $104,5 \mathrm{~cm}^{2}$ y la menor, de $8,25 \mathrm{~cm}^{2}$. En la recolección final, la mayor área fue de $103,5 \mathrm{~cm}^{2} \mathrm{y}$ de $1,25 \mathrm{~cm}^{2}$ la menor. No hubo diferencia significativa entre el área inicial y final de la herida ( $p=0,7695$; prueba de Wilcoxon). En la tabla 2 se describen los datos de localización, tipos y medidas de las heridas de la casuística.

Se verificó que al inicio del estudio, el promedio de la PCR sérica fue de $1,13 \pm 1,08 \mathrm{mg} / \mathrm{dl}(\mathrm{de} 0,27 \mathrm{mg} / \mathrm{dl}$ a $3,82 \mathrm{mg} / \mathrm{dl}$ ) $y$ al final fue de $0,88 \pm 0,44 \mathrm{mg} / \mathrm{dl}$ (de 0,18 a $1,46 \mathrm{mg} / \mathrm{dl}$ ). Sin embargo, no se halló diferencia entre los valores séricos de PCR incial y final $(p>0,05)$.

Cuando se comparó el área de la herida con los niveles séricos de PCR, se observó una débil correlación entre el área inicial de la herida y la PCR inicial $(\mathrm{r}$ de Spearman $=0,05183)$ y el área final de la herida y la PCR final $(\mathrm{r}$ de Spearman $=0,3587)$. Sin embargo, con el aumento del área de la herida, hubo un incremento de los niveles de PCR, y con la disminución del área de la herida, una reducción en los niveles de PCR, como se muestra en la figura 1 .
Tabla 1. Características sociodemográficas y clínicas de los pacientes con heridas crónicas en seguimiento ambulatorio. $(\mathrm{N}=10)$. São José do Rio Preto, SP, Brasil, 2016

\begin{tabular}{|c|c|c|}
\hline Características de los pacientes & $\mathbf{N}$ & $(\%)$ \\
\hline \multicolumn{3}{|l|}{ Sexo } \\
\hline Mujeres & 6 & 60 \\
\hline Hombres & 4 & 40 \\
\hline Total & 10 & 100 \\
\hline \multicolumn{3}{|l|}{ Edad (años) } \\
\hline$>50$ & 4 & 40 \\
\hline $50-84$ & 6 & 60 \\
\hline Total & 10 & 100 \\
\hline \multicolumn{3}{|l|}{ Escolaridad } \\
\hline Secundaria completa & 2 & 20 \\
\hline Secundaria incompleta & 3 & 30 \\
\hline Primaria completa & 2 & 20 \\
\hline Primaria incompleta & 2 & 20 \\
\hline Analfabeto & 1 & 10 \\
\hline Total & 10 & 100 \\
\hline \multicolumn{3}{|l|}{ Tabaquismo } \\
\hline Sí & 1 & 10 \\
\hline No & 9 & 90 \\
\hline Total & 10 & 100 \\
\hline \multicolumn{3}{|l|}{ Enfermedades asociadas } \\
\hline Diabetes & 2 & 20 \\
\hline Hipertensión & 3 & 30 \\
\hline Ninguna & 5 & 50 \\
\hline Total & 10 & 100 \\
\hline \multicolumn{3}{|l|}{ Clasificación según IMC } \\
\hline Eutrofia & 2 & 20 \\
\hline Delgadez & 1 & 10 \\
\hline Sobrepeso & 3 & 30 \\
\hline Obesidad & 4 & 40 \\
\hline Total & 10 & 100 \\
\hline
\end{tabular}

IMC: índice de masa corporal.

Fuente: Datos de la investigación, 2016

Tabla 2. Características de las heridas de los pacientes con heridas crónicas en seguimiento ambulatorio (N = 10). São José do Rio Preto, SP, Brasil, 2016

\begin{tabular}{|c|c|c|c|c|c|c|c|c|c|c|c|c|c|}
\hline $\begin{array}{c}\text { Pa- } \\
\text { ciente }\end{array}$ & $\begin{array}{l}\text { Edad } \\
\text { (años) }\end{array}$ & Sexo & Тіро & $\begin{array}{l}\text { Tiempo } \\
\text { (meses) }\end{array}$ & Local & $\begin{array}{l}\text { Área } \\
\text { inicial } \\
\left(\mathrm{cm}^{2}\right)\end{array}$ & $\begin{array}{c}\text { Área } \\
\text { final }\left(\mathrm{cm}^{2}\right)\end{array}$ & $\begin{array}{l}\text { Exsudato } \\
\text { inicial }\end{array}$ & $\begin{array}{l}\text { Exsudato } \\
\text { final }\end{array}$ & $\begin{array}{l}\text { Tejidos presen- } \\
\text { tes (inicial) }\end{array}$ & $\begin{array}{l}\text { Tejidos } \\
\text { presentes } \\
\text { (final) }\end{array}$ & $\begin{array}{l}\text { |lnfección } \\
\text { (inicial) }\end{array}$ & $\begin{array}{l}\text { Infección } \\
\text { (final) }\end{array}$ \\
\hline 1 & 65 & $\mathrm{~F}$ & Vasculogénico & 120,00 & Pierna & 9,3 & 18,0 & Seropurulento & Seropurulento & Esfacelo & Esfacelo & No & No \\
\hline 2 & 84 & $\mathrm{~F}$ & Dehiscencia & 1,10 & Abdomen & 8,25 & 1,25 & Purulento & Seroso & Esfacelo & Granulación & Sí & No \\
\hline 3 & 61 & $\mathrm{~F}$ & Vasculogénico & 24,00 & Pierna & 104,5 & 103,5 & Purulento & Purulento & $\begin{array}{c}\text { Esfacelo/ } \\
\text { violáceo }\end{array}$ & $\begin{array}{c}\text { Esfacelo/ } \\
\text { violáceo }\end{array}$ & Sí & Sí \\
\hline 4 & 32 & M & $\begin{array}{l}\text { Micosis } \\
\text { fungoide }\end{array}$ & 2,00 & Abdomen & 11,7 & 19,25 & Seroso & Purulento & Desvitalizado & Desvitalizado & No & Sí \\
\hline 5 & 40 & M & Vasculogénico & 14,00 & Pierna & 121,0 & 110,0 & Seropurulento & Seropurulento & Esfacelo & $\begin{array}{c}\text { Esfacelo/ } \\
\text { violáceo }\end{array}$ & Sí & Sí \\
\hline 6 & 76 & M & Dehiscencia & 1,23 & Muslo & 9,9 & 7,5 & Purulento & Seroso & Esfacelo & Granulación & Sí & No \\
\hline 7 & 41 & $F$ & Trauma & 111,10 & Pierna & 10,5 & 15,75 & Seroso & Seropurulento & Esfacelo & $\begin{array}{c}\text { Esfacelo/ } \\
\text { violáceo }\end{array}$ & No & Sí \\
\hline 8 & 33 & M & Trauma & 27,00 & Pierna & 12,0 & 34,0 & Purulento & Seropurulento & $\begin{array}{c}\text { Esfacelo/ } \\
\text { violáceo }\end{array}$ & $\begin{array}{c}\text { Esfacelo/ } \\
\text { violáceo }\end{array}$ & Sí & Sí \\
\hline 9 & 65 & $\mathrm{~F}$ & Trauma & 36,00 & Pierna & 12,0 & 20,0 & Seropurulento & $\begin{array}{l}\text { Serosanguino- } \\
\text { lento }\end{array}$ & $\begin{array}{l}\text { Violáceo/hiper- } \\
\text { granulación }\end{array}$ & $\begin{array}{l}\text { Hipergranula- } \\
\text { ción }\end{array}$ & Sí & Sí \\
\hline 10 & 76 & F & Vasculogénico & 1,00 & Pierna & 28,0 & 18,0 & Sanguinolento & Sanguinolento & Granulación & Epitelización & No & No \\
\hline
\end{tabular}




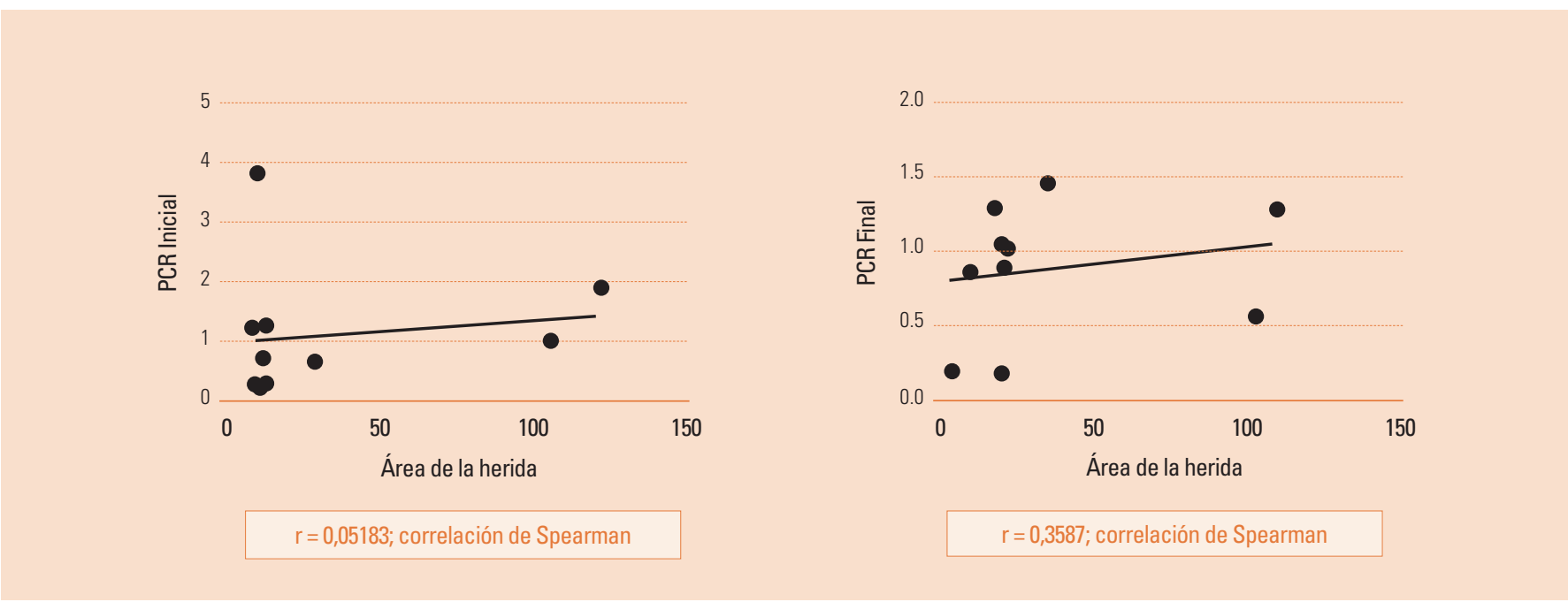

Figura 1. Correlación entre el área de la lesión inicial y la PCR inicial y el área final y la PCR final de los pacientes con heridas crónicas en seguimiento ambulatorio ( $N=10)$. São José do Rio Preto, SP, Brasil, 2016.

En cuanto al uso de antibiótico sistémico, el 30\% lo estaba utilizando y el $50 \%$ reportó um uso reciente. No hubo reportes sobre el uso de corticoesteroide.

En cuanto a los microorganismos encontrados en las heridas en la recolección inicial, se constató que el 70\% de los pacientes presentaron Staphylococcus aureus; un 50\%, Pseudomonas aeruginosa; un 20\%, Streptococcus agalactiae; un 10\%, Enterococcus faecalis; um 10\%, Morganella morganii; um 10\%, Acinetobacter haemolyticus; un 10\%, Escherichia coli, y un $10 \%$ Candida parapsilosis. Por su parte, en la recogida final, el $60 \%$ de los pacientes presentaron Staphylococcus aureus; el 60\%, Pseudomonas aeruginosa; el 20\% Klebsiella pneumoniae; el 20\%, Acinetobacter haemolyticus; el 10\%, Morganella morgani; el 10\%, Streptococcus agalactiae; un $10 \%$, Eschericia coli, y um 10\%, Pseudomonas mendocina.

En cuanto a los microorganismos encontrados, se observó que los pacientes 2 y 9 presentaron en su microbiota inicial Streptococcus agalactiae y la inhibición de este microorganismo en la recolección final. El paciente 7 presentó en la recogida inicial Staph. aureus y P. aeruginosa. Además de la permanencia de las dos bacterias en su microbiota inicial, se caracterizó la presencia de la Str. agalactiae en la recolección final. En este sujeto se observó una alteración del tejido de la herida, un aumento del área de la lesión caracterizado por un tejido desvitalizado, violáceo y aumento de los niveles de PCR. La herida presentaba compromiso vasculogénico, cronicidad y un tiempo de duración de 10 ańos.

Los pacientes 5 y 10 se caracterizaron por presentar úlceras de origen vasculogénico, sin uso de sistema de compresión o contención, presentaron una reducción en las medidas del largo y ancho de la herida, respectivamente de $11,0 \mathrm{~cm} \times 11,0 \mathrm{~cm}$ a $10,0 \times 11,0 \mathrm{~cm}$ y de $8,0 \mathrm{~cm} \times 3,5$ $\mathrm{cm}$ a $6,9 \mathrm{~cm} \times 3,0 \mathrm{~cm}$, con la presencia y permanencia de Staph. aureus en la recolección final, respectivamente.

Los sujetos 2 y 6, caracterizados por una herida por dehiscencia, estaban en tratamiento con un antibiótico sistémico y se observó una evolución significativa en las medidas de largo y ancho, disminución de los niveles de PCR y evolución de la herida del tejido necrótico para granulación.

Se verificó en el paciente 2 la presencia del Staph. aureus y Str. agalactiae en la recolección inicial, y la permanencia del Staph. aureus en la recolección final; y en el paciente 6 se observó la presencia de P. aeruginosa en la recolección inicial y final.
Caracterizado por una herida por micosis fungoide y en tratamiento con antibiótico sistémico, el paciente 4 presentó en su microbiota inicial Candida parapsilosis; se observó el aumento de las medidas en lo referente al largo, ancho y profundidad de la herida. Inicialmente, la herida se presentó cubierta por esfacelo y durante el tratamiento, con el medio húmedo proporcionado por la cobertura de hidroalginato con plata asociado a la gran calidad de exudado, se produjo el desbridamiento autolítico del tejido necrosado, caracterizando el aumento de la herida y considerado como una evolución positiva para el tratamiento y proceso de cicatrización. De esta forma, en la recolección final se verificó la presencia de Klebsiella pneumoniae, Acinetobacter haemolyticus y Pseudomonas mendocina.

\section{Y DISCUSIÓN}

En el presente estudio, la mayoría de los pacientes era del sexo femenino y la úlcera vasculogénica fue el tipo de herida más frecuente. Este hallazgo también se produjo en el estudio de Brito et $\mathrm{al}^{13}$, en el cual, de los 51 pacientes estudiados, 34 (66,7\%) eran mujeres y presentaban heridas vasculogénicas. De hecho, las directrices clínicas ${ }^{14}$ han considerado que las úlceras vasculogénicas representan desafíos significativos para pacientes y sistemas de salud, pues son frecuentes, caras de gestionar, recurrentes y pueden persistir durante meses o años. Suelen causar un impacto negativo en varios aspectos de la vida diaria del paciente, ocasionando depresión, ansiedad y aislamiento social. El dolor, la exudación en exceso, el olor, la movilidad restringida y las alteraciones del sueño pueden ser particularmente desafiadores.

La hipertensión fue la comorbilidad observada con mayor frecuencia, y en relación con las variables antropométricas analizadas es importante destacar que la mayoría de los pacientes presentó exceso de peso ( $30 \%$ con sobrepeso y $40 \%$ con obesidad). Un hallazgo similar se encontró en el estudio realizado por Santos et al. ${ }^{15}$, con 36 pacientes com úlcera de pierna crónica, en el cual las enfermedades crónicas que más prevalecieron fueron la hipertensión arterial sistémica y la obesidad (52,8\% y 33,3\% de ellos, respectivamente). De hecho, la obesidad es un factor que amplifica la complejidad del microambiente de la herida. Durante las incursiones respiratorias 
en el paciente obeso, el diafragma no consigue bajar completamente debido al tejido adiposo abdominal y a que la expansibilidad torácica se encuentra disminuida, lo que causa hiperventilación; entretanto, existe una disminución de la capacidad vital y, en consecuencia, una disminución del nivel de oxígeno en los tejidos ${ }^{10}$. De esta forma, la presión de oxígeno en la herida del paciente obeso es menor, debido a la no vascularización del tejido adiposo y a la dificultad de ventilación y perfusión ${ }^{16}$.

En el presente estudio, el promedio de duración de las heridas fue de 19 meses. Por tanto, estas heridas son consideradas crónicas y el proceso de cicatrización es prolongado, incompleto y ocurre de forma desordenada, con un resultado, tanto anatómico como funcional, inadecuado ${ }^{1}$.

El tratamiento de una herida infectada y las enfermedades concomitantes debe considerarse, por lo que es necesaria una buena higiene, desbridamiento y limpieza de la herida con el fin de reducir la carga bacteriana, acortar el tiempo de cicatrización y minimizar las consecuencias para los pacientes y para el sistema de salud ${ }^{6}$. Cuando no se consigue obtener una cicatrización suficiente después de 4 semanas de tratamiento estándar, debe considerarse la reevaluación de la patología subyacente y la necesidad de agentes terapéuticos avanzados ${ }^{17}$.

Otro hallazgo de este estudio fue la débil correlación entre el área inicial de la herida y la PCR sérica inicial, y entre el área final de la herida y la PCR sérica final. No obstante, con el aumento del área de la herida se observó un aumento de los niveles de PCR, y con la disminución del área de la herida, una reducción en los niveles de PCR.

Descubierta en 1930, la PCR es una proteína de la fase aguda, cuya concentración sérica aumenta o disminuye un $25 \%$ en los estados inflamatorios. En general, las inflamaciones leves y las infecciones virales conducen a elevaciones en el rango de $1-4 \mathrm{mg} / \mathrm{dl}$; en el caso de inflamaciones más graves e infección bacteriana, las concentraciones séricas oscilan entre 4 y $20 \mathrm{mg} / \mathrm{dl}^{10}$.

En el estudio de Queiroz et al. ${ }^{18}$, realizado en pacientes con lesión por presión, se observó que los valores de PCR encontrados en el $96,1 \%$ de los pacientes eran superiores a los esperados, lo que indica la posible existencia de un proceso inflamatorio en las lesiones relacionadas con las enfermedades de base. En dichos pacientes, se identificó una producción media a gran cantidad de exudado seroso y sanguinolento, en el 33\% y 26\%, respectivamente.

Todas las heridas pueden adquirir microrganismos, y si las condiciones físicas y nutricionales del huésped son las adecuadas, el proceso de cicatrización ocurre normalmente. Entretanto, algunas veces la carga microbiana se multiplica y sin la respuesta adecuada del huésped podría causar daños e iniciar la infección ${ }^{19}$.

Se observó que los sujetos 2, 9 y 7 que presentaron Str. agalactiae en su microbiota eran del sexo femenino. En un estudio retrospectivo, con un relevamiento epidemiológico y cuantitativo de datos, se identificó que de los 141 cultivos positivos evaluados, Str. agalactiae fue predominante en el sexo femenino $(82,27 \%)$ y con un rango promedio de edad entre los 14 y 44 años $^{20}$. Str. Agalactiae, también conocido como estreptococo del grupo B, es parte de la flora vaginal normal y del trato gastrointestinal bajo en el $5 \%$ al $25 \%$ de las mujeres $^{21}$.

La bacteria predominante en la investigación fue $S$. aureus, presente en el $70 \%$ de la recolección inicial y en el $60 \%$ de la recolección final. $S$. aureus es un microorganismo presente en la colonización normal de la flora humana y también está presente, con frecuencia, en infecciones de la comunidad y hospitalarias. Es un patógeno capaz de formar una biopelícula fuerte que mantiene la infección crónica perjudicando la cicatrización de la herida y el aumento del desarrollo de la resistencia a los antibióticos ${ }^{22,23}$.

En un estudio se evaluó la eficacia del curativo compuesto por carboximetilcelulosa con un 1,2\% de plata frente a dos especies: $S$. aureus y $P$. aeruginosa, en un fluido simulado de heridas después de 24 horas. Los datos fueron trazados a través de curvas de calor acumulado. Se observó el crecimiento de $S$. aureus y $P$. aeruginosa cuando no existe la actuación del curativo antimicrobiano asociado a la plata ${ }^{24}$.

Para el tratamiento inicial, el consenso de infección de heridas sugiere un "período de desafío" de 2 semanas, con la finalidad de observar la eficacia del vendaje con plata ${ }^{19}$. Sin embargo, se observa en este estudio que no hubo alteración significativa de los microorganismos encontrados antes y después del tratamiento, lo que apunta a la necesidad de evaluación del tipo, cantidad y disponibilidad de la plata encontrada en las cubiertas.

De esta forma, un abordaje más basado en el desempeńo para el uso de curativos puede ser orientado por cuestiones básicas tales como: cuál es la acción del curativo, qué tan bien hace, qué precisa el/la paciente, que hay disponible en el mercado y qué es práctico ${ }^{25}$.

\section{У CONCLUSIÓN}

Este estudio mostró inhibición de algunos microorganismos presentes en las heridas en la recolección inicial, crecimiento de especies y géneros diferentes comparados con la recolección final, y $S$. aureus como la bacteria predominante en la mayoría de los pacientes en la recolección inicial y final. La correlación de los niveles séricos de PCR y las dimensiones de la herida fueron débiles y no significativas, pero positivas

\section{Conflicto de intereses}

No existe ninguna relación financiera o personal que pueda dar origen a un conflicto de intereses de alguno de los autores con relación al artículo publicado.

\section{BIBLIOGRAFÍA}

1. Vowden P.Hard-to-heal wounds Made Easy. Wounds Int 2011:2(4):1-6.

2. Ferreira MC, Tuma P Jr, Carvalho VF, Kamamoto F. Complex wounds. Clinics (Sao Paulo). 2006;61(6):571-8.

3. Schultz GS, Sibbald RG, Falanga V, Ayello EA, Dowsett C, Harding $\mathrm{K}$, et al. Wound bed preparation: a systematic approach to wound management. Wound Repair Regen. 2003;11 Suppl 1:S1-28.

4. Gottrup F, Apelqvist J, Bjarnsholt T, Cooper R, Moore Z, Peters EJ, et al. Antimicrobials and Non-Healing Wounds. Evidence, controversies and suggestions-key messages. J Wound Care. 2014;23(10):477-82
5. Roberts CD, Leaper DJ. Antiseptic resistance: antimicrobial stewardship and silver dressings Wounds Int. 2017;8(2):27-31.

6. Wounds International. International consensus. Appropriate use of silver dressings in wounds. An expert working group consensus. London: Wounds International; 2012

7. Hebeisha A, El-Rafie MH, EL-Sheik MA, Seleem AA, El-Naggar ME. Antimicrobial wound dressing and anti-inflammatory efficacy of silver nanoparticles. Int J Biol Macromol. 2014;65:509-15.

8. World Health Organization. Obesity: preventing and managing the global epidemic. Report of a World Health Organization Con- sultation. Geneva: World Health Organization, 2000. p. 256. WHO Obesity Technical Report Series, n. 284.

9. Lipschitz DA. Screening for nutritional status in the elderly. Prim Care. 1994:21:55-67.

10. Clyne B, Olshaker JS. The C-reactive protein. J Emerg Med. 1999;17(6):1019-25.

11. Dealey C. Produtos para tratamento de feridas. Cuidando de feridas. 3. ${ }^{\mathrm{a}}$ ed. São Paulo: Atheneu; 2008. p. 19 e 83.

12. Agência Nacional de Vigilância Sanitária. Microbiologia Clínica para 0 Controle de Infecção Relacionada à Assistência à Saúde. 
Módulo 4: Procedimentos Laboratoriais: da requisição do exame à análise microbiológica e laudo final. Brasília (DF): ANVISA; 2013

13. Brito CKD, Nottingham IC, Victor JF, Feitoza SMS, Slva MG, Amaral HEG. Úlcera venosa: avaliação clínica, orientaç̃̃es e cuidados com 0 curativo. Rev Rene. 2013;14(3):470-80.

14. Hardin K. Simplifying venous leg ulcer management: consensus recommendations. London: Wounds International; 2015

15. Dal Santos M, Franco S, Sanches FLZ, Rosalva R, Hacka J, Meottia N, et al. Caracterizacão Nutricional de Pacientes com Úlceras Crônicas de Membros Inferiores em Tratamento no Ambulatório de Feridas do Campus Cedeteg da UNICENTRO, Guarapuava-PR. UNOPAR Cient Ciênc Biol Saúde. 2015;17(1):13-9.

16. Wilson JA, Clark JJ. Obesity Impediment to Wound Healing. Crit Care Nurs 0. 2003;26(2):119-32

17. Frykberg RG, Banks J, Challenges in the Treatment of Chronic Wounds, Adv Wound Care (New Rochelle). 2015;4(9):560-82.
18. Queiroz VBB, Squizatto RH, Oliveira NC, Matta PRA, Poletti NAA. Avaliação dos níveis séricos de proteínas em pacientes com úlceras por pressão. Arq Ciênc Saúde. 2016:23(1 $89-92$

19. International Wound Infection Institute (IWII). International Consensus Update 2016 [homepage na Internet]. London (UK) 2016 [aceso 14 de marzo de 2017]. Wound Infection In Clinical Practice 2016. Principles of best practice; [aproximadamente 17 pantallas]. Disponible en: https://www.bbraun.com/content/ dam/catalog/bbraun/bbraunProductCatalog/CW_DK/da-dk/b2/ wound-infection-inclinicalpractice.pdf.bb-.36505659/wound-infection-inclinicalpractice.pdf

20. Rampelotto RF, Hörner R, Martini R, Nunes M, Razia L, Comiz T. Avaliação do perfil de sensibilidade aos antimicrobianos de Streptococcus Agalactiae isolados em um hospital universitário. Arq Ciênc Saúde. 2014:21(2)112-7.
21. Brooks GF, Butel JS, Morse SA. Jawetz, Melnick e Adelberg, Microbiologia Médica: um livro Médico Lang. 24. ${ }^{a}$ ed. São Paulo: MCGraw-Hill Interamericana do Brasil; 2009.

22 Wertheim HF, Melles DC, Vos MC, van Leeuwen W, van Belkum A, Verbrugh HA, et al. The role of nasal carriage in Staphylococcus aureus infections. Lancet Infect Dis. 2005;5(12):751-62.

23. Serra R, Grande R, Butrico L, Rossi A, Settimio UF, Caroleo B, et al. Chronic wound infections: the role of Pseudomonas aeruginosa and Staphylococcus aureus. Expert Rev Anti Infect Ther. 2015;13(5):605-13.

24. Said J, Dodoo CC, Walker M, Parsons D, Stapleton P, Beezer AE, et al. An in vitro testo of the efficacy of silver containing wound dressing agaisnt Staphylococcus aureus and Pseudomonas Aeruginosa in simulated wound fluid. Int J Pharm. 2014;28;462(1-2):123-8.

25. Ovington LG. Wound Care Products: How to Choose. Home Healthcare Nurse 2001:19(4):224-32. 